\title{
La paradoja del derecho a la vivienda en México: vivienda urbana nueva deshabitada, 1990-2010
}

\author{
Housing Right's paradox: uninhabited new urban housing in \\ Mexico, 1990-2010
}

Guadalupe Margarita González Hernández ${ }^{1}$

\section{Resumen}

Lejos de ser una política de fomento a la vivienda que se rige bajo el derecho a la vivienda digna, es una política de financiamiento en apoyo al capital inmobiliario. Bajo el amparo de la liberalización de créditos y reestructuración de las instituciones financieras hipotecarias, y sostenida por los trabajadores como la única realmente población objetivo, por su estabilidad laboral y seguridad financiera, la política de financiamiento de la vivienda se convierte en un éxito para la clase empresarial de la construcción, dejando a las ciudades con infinidades de nuevos problemas (mala calidad del stock de viviendas, segregación socioespacial, generación de violencias) y que aquí se ocupa sólo de uno: viviendas deshabitadas. Con datos censales de población y vivienda (1990-2010) y de los créditos ejercidos en México y sus entidades federativas, se demuestra que la mayor parte de ellos fueron ejecutados en las ciudades mexicanas mayores de cien mil habitantes porque son manchas urbanas que cumplen con el mercado cautivo de trabajadores con derecho a INFONAVIT y FOVISSSTE y con los ingresos necesarios para sustentar la rentabilidad del capital inmobiliario. Sin preocupación por la utilidad de la vivienda y la declaración al derecho a la vivienda por todos los residentes.

Palabras clave: Vivienda. Crédito hipotecario. México. Ciudades mexicanas.

\begin{abstract}
Far from being a promotion policy governing housing under the right to adequate housing is a policybased lending to real estate. Under the protection of credit liberalization and restructuring of financial institutions mortgage, and sustained by workers as the only really target population, job stability and financial security, policy housing finance becomes a success for the enterprise-class construction, leaving the city with an infinite number of new problems (poor quality housing stock, spatial segregation, violence generation) and here is concerned only one: uninhabited housing. Using data on population and housing census (1990-2010) and credits exercised Mexico and states, it is shown that most of them were executed in the Mexican cities over one hundred thousand inhabitants because they are urban spots that meet the captive market of workers entitled to INFONAVIT and FOVISSSTE and the income needed to sustain the profitability of real estate. No concern about the utility of housing and the declaration of the right to housing for all residents.
\end{abstract}

Keywords: Housing. Mortgage. Mexico. Mexican cities.

\footnotetext{
${ }^{1}$ Doctora en Ciencias Sociales por El Colegio de la Frontera Norte (COLEF, México), especialista en Estudios Urbanos. Docente investigadora de la Universidad Autónoma de Zacatecas (México) desde 1997 en las Unidades Académicas de Economía, Ciencias de la Salud, Ciencia Política y actualmente en Estudios del Desarrollo. Profesora invitada en la Universidad Autónoma de Guerrero, Instituto Tecnológico de Acapulco (México) y Universidad de La Rioja (España). Email: gmgonzh@yahoo.com.mx
} 


\section{Introducción}

Se demuestra que lejos de ser una política de fomento a la vivienda que se rige bajo el derecho a la vivienda digna, es una política de financiamiento en apoyo al capital inmobiliario. Bajo el amparo de la liberalización de créditos y reestructuración de las instituciones financieras hipotecarias, y sostenida por los trabajadores como la única realmente población objetivo, por su estabilidad laboral y seguridad financiera, la política de financiamiento de la vivienda se convierte en un éxito para la clase empresarial de la construcción, dejando a las ciudades con infinidades de nuevos problemas (mala calidad del stock de viviendas, segregación socioespacial, generación de violencias) y que aquí se ocupa sólo de uno: viviendas deshabitadas.

Desde la visión marxista, además de obtener plusvalor de la fuerza de trabajo en el proceso productivo, bajo el sistema de retención de salarios para ahorro de vivienda, los trabajadores sustentan el negocio inmobiliario mexicano. Bajo el pretexto de una vivienda digna, al trabajador se le confina una vivienda cada vez de menor calidad a un costo financiero alto. No obstante, éste tiene un límite al mostrar el fenómeno de viviendas deshbaitadas, nuevas. Mientras al residente urbano, alejado de la relación capital trabajo, sigue ausente y excluido de las políticas de fomento a la vivienda.

Con datos censales de población y vivienda por dos décadas (1990-2010) y con datos sobre los créditos ejercidos en México y sus entidades federativas, se demuestra que la mayor parte de ellos fueron ejecutados en las ciudades mexicanas mayores de cien mil habitantes porque son manchas urbanas que cumplen con el mercado cautivo de trabajadores con derecho a INFONAVIT y FOVISSSTE y con los ingresos necesarios para sustentar la rentabilidad del capital inmobiliario. Sin preocupación por la utilidad de la vivienda y la declaración al derecho a la vivienda por todos los residentes.

\section{Del Derecho a la Vivienda al Derecho al Crédito}

Tanto las legislaciones, como las políticas de fomento a la vivienda y declaratorias universales de derechos humanos convergen en que la vivienda es un derecho universal.

No obstante, en la actualidad, la vivienda tiene un problema de democracia, crecimiento y equidad. Bajo esta idea las políticas de fomento a la vivienda se enfocan en principios liberales para dotar vivienda a los más desprotegidos, más pobres y más vulnerables (ETCHEGARAY, 1997). Desde su perspectiva, las políticas de fomento a la vivienda de los últimos años han detenido la ocupación ilegal del suelo, han dado solución habitacional a la mayor parte de las familias, incluso las de menores ingresos y han llevado servicios básicos a la mayor parte de las viviendas (DUCCI, 1997). No obstante, los datos evidencian que:

a) fueron los capitalistas relacionados con la industria de la construcción inmobiliaria los grandes beneficiarios: compraron reservas de suelo en las periferias urbanas.

b) el Estado ha tenido que centrar su política de financiamiento habitacional en la dimensión del déficit acumulado;

c) mayor déficit en la calidad de vida en la vivienda de interés social (RODRÍGUEZ; SUGRANYES, 2004, 2011). El promedio de las dimensiones de la vivienda en México ha caído de $56.6 \mathrm{~m}^{2}$ en 1990 a $48.8 \mathrm{~m}^{2}$ en 2010 (SÁNCHEZ, 2012).

d) el costo social y urbano de esta producción masiva de viviendas sociales, que incluye costos de localizar servicios y equipamiento en la periferia (no considerados en los proyectos de vivienda social) versus las ventajas que ofrecen las áreas ya consolidadas de la ciudad,

e) segregación a localizar en espacios específicos a similares grupos sociales y separarlos de los distintos, 
f) fragmentación al seleccionar y diferenciar los espacios urbanos a través de fraccionamientos, e

g) inseguridad y la percepción de inseguridad asociadas a la convivencia como práctica de exclusión (RODRÍGUEZ; SUGRANYES, 2004, 2011).

En todo caso, la relación entre el Estado, bajo la égida del sector público, y los capitales inmobiliarios en la producción de vivienda de interés social se torna un asunto político en determinar, no sólo la orientación de las demandas de vivienda y acceso al suelo de los residentes de las ciudades y orientar sus estructuras urbanas (GARCÍA, 2010), sino apropiarse de los trabajadores como mercado cautivo bajo la tutela de las prestaciones sociales como derecho humano y laboral.

\section{Instrumentalización del Crédito a la Vivienda en México}

El proceso de industrialización fomentado en la posguerra, basado en la exportación de materias primas e importación de bienes de capital orientó los flujos de capitales y personas a las ciudades, en especial a las grandes: México, Guadalajara y Monterrey. La demanda de vivienda y suelo se convirtió en un problema que el gobierno tuvo que solucionar a través de la creación de instituciones hipotecarias.

En México, aunque los programas de fomento al crédito de la vivienda datan desde 1963, donde se buscó promover y regular la participación de la banca privada en el sector, en la cual se empleó el ahorro público a través el sistema bancario creando el Fondo de Operación y Financiamiento Bancario a la Vivienda (FOVI), por un lado y el Instituto del Fondo Nacional para la Vivienda para los Trabajadores (INFONAVIT) y el Fondo de la Vivienda del Instituto de Seguridad y Servicios Sociales de los Trabajadores del Estado (FOVISSSTE), a través de las prestaciones relacionadas al trabajo, por el otro, se consolidó el proceso (TORRES;
EIBENSCHUTZ, 2005) lentamente y en forma desigual territorialmente: el capital inmobiliario creó sólo el 17 por ciento y el Estado el 0.42 por ciento del stock habitacional nacional durante la década de los sesenta donde la ciudad de México concentró la mayor parte (GARCÍA, 2010).

A inicios de la década de los setenta, la estabilidad de precios, el crecimiento sostenido del producto interno bruto y el fortalecimiento del Estado como agente económico directo permitió la creación de un engranaje legal para controlar, regular y planificar la inversión y oferta de vivienda de interés social. Situación que permitió al Estado ofrecer crédito barato a una reducida parte de la población urbana principalmente de ingresos medios y bajos.

La crisis a mediados de la década obligó al sistema de financiamiento de la vivienda estatal orientar su cobertura social hacia los de mayor capacidad de pago. Al mismo tiempo, los organismos supranacionales exigieron al Estado mexicano fortalecer la propiedad privada (y el impulso de la vivienda propia nueva) como un mecanismos de defensa contra la amenaza comunista. No obstante, la cobertura resultó limitada y más ante la reducción de recursos, cuando la banca se liberó de destinar parte de la captación de los recursos a FOVI, y los limitó a los préstamos provenientes del Banco Mundial (GARCÍA, 2010).

Es hasta 1993 que se dio el proceso de reestructuración para que estas instituciones hipotecarias públicas se convirtieran en instrumentos netamente financieros y dejar al capital privado, la construcción de viviendas para los trabajadores. En teoría, tales reformas pretendían mejorar la eficiencia del INFONAVIT y FOVISSSTE, agilizar la recuperación de créditos, transparentar sus gestiones y sobre todo, "facilitar el derecho del trabajador para elegir su vivienda en el mercado." (GARCÍA, 2010, p. 42). En contraste, el Fondo Nacional de Habitaciones Populares (FONHAPO) se encargó del mejoramiento, ahorro y subsidios a la vivienda progresiva y sobre todo a la vivienda 
social y rural (GONZÁLES, 2002; TORRES; EIBENSCHUTZ, 2005).

La vivienda social perdió, bajo estas reformas, importancia "como factor de cooptación política" por parte del Estado, pero permitió la apropiación del mercado inmobiliario por el capital. El papel del sector público se enfocó en facilitar, bajo la responsabilidad de ser únicamente promotor, la actividad, dirigiéndose a establecer las condiciones generales para que el capital privado y el sector social la asumieran (MEJÍA, 1997).

A raíz de la crisis del 95 y bajo los lineamientos del Banco Mundial, el INFONAVIT dejó de ser promotor de la vivienda para ser facilitador, creando un mercado cautivo para los capitales inmobiliarios, gracias a los recursos provenientes del salario indirecto del trabajador. Asimismo, dicho instituto vendió sus reservas territoriales y, con la modificación del artículo 27 Constitucional, el capital inmobiliario adquirió tierras ejidales en las periferias de las ciudades mexicanas, para construir lotes homogéneos al interior $\mathrm{y}$ diferenciados respecto al exterior de fraccionamientos de viviendas, dejando de lado el control de calidad que había estipulado el INFONAVIT tiempo atrás.

La orientación del beneficiario también cambió: antes de su reforma el INFONAVIT dio cobertura a aquellos con ingresos menores a dos salarios mínimos (equivalente a diez dólares americanos diarios al tipo de cambio del mes de abril del 2013) en un 83 por ciento. A darse la modificación de su organización, la cobertura se dio a los de ingresos mayores de dos salarios mínimos en un 77 por ciento (GARCÍA, 2010).

En la actualidad, la vivienda en México, se puede adquirir bajo distintos tipos de financiamiento: a través de instituciones y organismos hipotecarios, instituciones de fomento a la vivienda rural y la autoconstrucción bajo el esquema de vivienda nueva, vivienda usada, mejoramiento, ampliación, lote con servicio y pie de casa.

Bajo esta configuración se encuentran distintos actores que socializan el fomento de la vivienda: desarrolladores, intermediarios financieros privados (bancos y las Sociedades Financieras de Objeto Limitado -SOFOCLES-), intermediarios financieros públicos (INFONAVIT, FOVISSSTE, Sociedad Hipotecaria Nacional -SHF-, FONHAPO y Comisión Nacional de la Vivienda, CONAVI), gobiernos federal, estatal y municipal y productores sociales de vivienda (FUNDACIÓN CENTRO DE INVESTIGACIÓN Y DOCUMENTACIÓN DE LA CASA, 2010; GONZÁLES, 2002).

La producción social de la vivienda ha sido predominante en la construcción de vivienda nueva al acaparar el 55 por ciento de los créditos de 1983 a 2003 otorgados en el país (TORRES; EIBENSCHUTZ, 2005). Es de atención principal, por tanto, el crédito a la vivienda nueva, ya que en México, en el período de interés (1990-2010), acaparó el 30 por ciento en 2010; 60 por ciento en 2000 y 40 por ciento en 1990 de los créditos hipotecarios otorgados (COMISIÓN NACIONAL DE VIVIENDA, 2013).

\section{La Vivienda como Apropiación del Valor de Cambio del Suelo y del Plusvalor del Trabajador}

Según la teoría de localización, el valor artificial dado al suelo, bajo la renta monopólica, extensión, singularidad y localización, permite encarecer su precio. Concretamente, en las ciudades, los valores del suelo en compra y venta se elevan de acuerdo a la proximidad a centros de comercios y servicios, equipamiento urbano o amenidades.

Con el fin de maximizar las ganancias, los capitalistas inmobiliarios buscarán, en la construcción de la vivienda social, reducir costos, no sólo al localizarlas lo más lejos posible de los altos precios del uso del suelo, sino en su constitución física (ENGELS, 1873; O'SULLIVAN, 1996).

Según Engels (1873), la vivienda, a inicios de la etapa capitalista, era un rasgo de relaciones anteriores al capitalismo, porque era un mecanismo 
de sujeción del proletariado. La emancipación del proletariado significó quedarse sin nada, libre para vender exclusivamente su fuerza de trabajo.

Por ello, el problema de la vivienda en esa época consistía en la no provisión de ella para los proletariados y tener que arrendarla. Ahí es, bajo un sistema indirecto, donde se da una estafa:

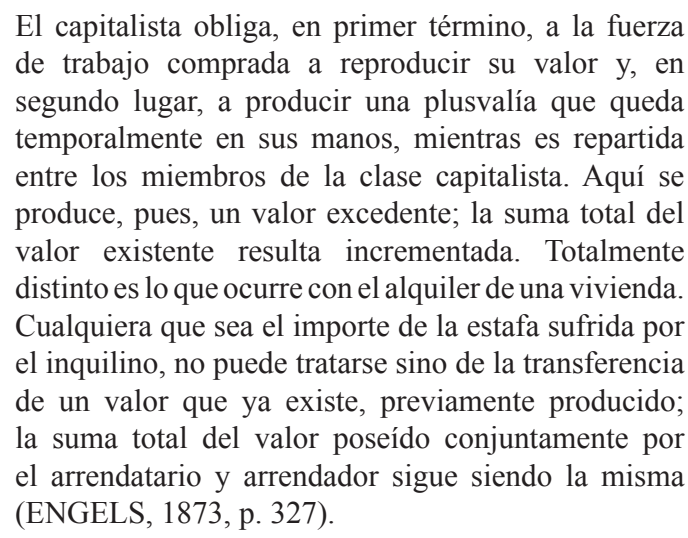

Lo rescatable de esto es que, en el sistema capitalista, la extracción de plusvalor sólo puede ser a través del proceso productivo y el resto de las actividades económicas (distribución, consumo, entretenimiento) sólo lo transfieren. En la actualidad, bajo el proceso de reestructuración económica donde la flexibilidad laboral y la introducción de la tecnología como formas de reducir el costo variable implica desproveer de su empleo al proletariado.

No obstante, puede surgir, que bajo la dinámica de rentabilizar al capital de otras actividades (como la producción de la vivienda), puede depender exclusivamente de la relación capital-trabajo, bajo la transferencia de valor (en una parte de su salario).

El proceso de restructuración de la economía, introducido para mantener a flote la tasa de ganancia y basado en la introducción de nuevas tecnologías, provocó la flexibilización en el proceso productivo y afectó la contratación de la fuerza de trabajo en dos formas. La primera, mediante un proceso más intensivo de su uso, con un salario más bajo, jornadas más largas y ausencia de prestaciones de seguridad social. Los trabajadores que permanecieron en el proceso productivo se vieron, con el paso del tiempo, imposibilitados de ahorrar; su salario, incluso, ya no cubrió sus necesidades más básicas.

No obstante, el sistema de seguridad social siguió quitándole su parte proporcional para el crédito de la vivienda. La segunda, a través del despido masivo de trabajadores industriales que no fueron ya requeridos y se vieron inmersos en el desempleo, subempleo y autoempleo en sectores menos rentables y con menor productividad, como los servicios que dieron cabida a una inmensa precarización de su trabajo, con jornadas interminables de trabajo, ingresos magros y nulas posibilidades de prestaciones sociales que permitan su reposición y reproducción como clase social y seres humanos. En este sector, es imposible acceder a una vivienda si no se cuenta con un sistema de ahorro altamente rentable.

El Estado, por su parte, lejos de retirarse de la economía como pregona la corriente teórica neoliberal, ha reconfigurado su función en favor del capital. Bajo el principio de la eficiencia y la transparencia de los recursos, el Estado ha regulado el ahorro para la vivienda de los trabajadores a través de intermediarios inmobiliarios, dando al trabajador la oportunidad de escoger libremente su vivienda cuando en el período antecesor el organismo regulador de la vivienda se la dotaba.

Bajo esta dinámica, la política actual de fomento de la vivienda en México, depende completamente de los trabajadores (GARCÍA, 2010; GONZÁLES, 2002). Dándose una transferencia de valor, desde la esfera de la producción a la producción de vivienda para el trabajador, sujeto a sistemas de crédito altamente nocivos para su reproducción (créditos a largo plazo, castigos por carteras vencidas) como fuerza de trabajo. El capital inmobiliario se ocupa, por tanto, de proveer principalmente vivienda nueva (bajo este sistema no es rentable la usada) al trabajador, dejando de lado al que cumple funciones económicas bajo formas no capitalistas.

No obstante, el trabajador, ante el actual sistema de desmantelamiento de prestaciones sociales y sus 
formas de organización sindical, ha disminuido su volumen como posible demanda de vivienda del capital inmobiliario. Se reduce el trabajador que se convierte en consumidor de las viviendas nuevas, sobre todo si su costo se incrementa por su precio monopólico.

Mientras tanto, el capitalista incrementa su oferta de vivienda, bajo la reducción de los costos salariales de sus trabajadores y calidad de los materiales utilizados. Bajo la protección del Estado que le asegura el ahorro del trabajador, la capacidad instalada de la producción de vivienda se da muy por encima del reducido monto de trabajadores como mercado objetivo. El resultado, el excedente de viviendas producidas.

Para el trabajador asalariado con prestaciones laborales se convierte en una carga pesada por treinta años y al reducirle su salario en un treinta y cinco por ciento mensual.

\section{Créditos a la Vivienda Nueva en México (1990-2010).}

En la actualidad, los datos sobre la cantidad de créditos que se destinan a la compra de vivienda nueva para las ciudades mexicanas sólo se publican a nivel estatal (COMISIÓN NACIONAL DE VIVIENDA, 2013), no obstante, para el período de análisis (1990-2010) y relacionándolo con los datos censales sobre población y vivienda, se pueden deducir algunas ideas y tendencias sobre las ciudades mexicanas. Para ello, es imprescindible analizar la situación a nivel nacional.

La gráfica 1 muestra el comportamiento de los créditos otorgados a los pobladores de México por el lapso de los últimos veinte años. La proporción de créditos destinados a vivienda nueva son prioridad en las políticas públicas federales desde los años setenta se considera que la vivienda nueva es digna de acuerdo a los derechos universales y constitucionales mexicanos (MEXICO, 2007). De acuerdo con los datos nacionales, los créditos a la vivienda nueva tuvieron un comportamiento variado en los últimos años, pero desde 1999 hasta el 2007, acapararon más del cincuenta por ciento de los créditos totales otorgados en México, dejando de lado los créditos a la vivienda rural, vivienda usada, ampliación y mantenimiento de la vivienda actual. Los datos más que cualquier discurso manifestaron en este período, que la prioridad en la construcción y distribución de vivienda no fueron los mexicanos más necesitados, los más marginados o los más pobres, sino los mexicanos que desean estrenar una vivienda nueva. 
Gráfica 1 - Créditos totales y para vivienda nueva en México, 1990-2010

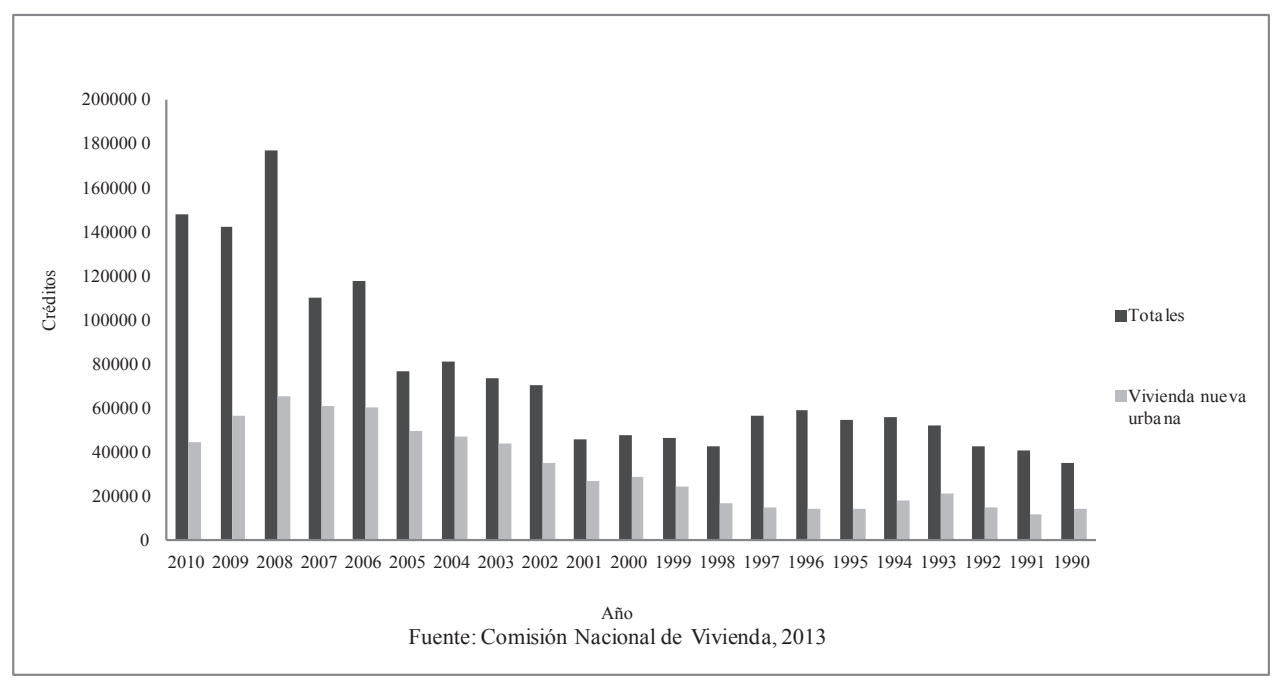

Fuente: Comisión Nacional de Vivienda (2013).

La década de los noventa trasmitió drásticamenteylabanca múltiple prácticamente claramente la adaptación y reestructuración se retiró de la actividad (GONZÁLES, 2002). de la nueva forma de destinar los créditos, Posteriormente, se nota un aumento paulatino siendo su punto más crítico en 1996 a raíz de la del crédito, principalmente en la primera profundización de la crisis económica suscitada década del siglo XXI, dando su punto álgido en 1995 (véase gráfica 2). La oferta disminuyó el año 2008.

Gráfica 2 - Crédito para vivienda nueva urbana en México, 1990-2010

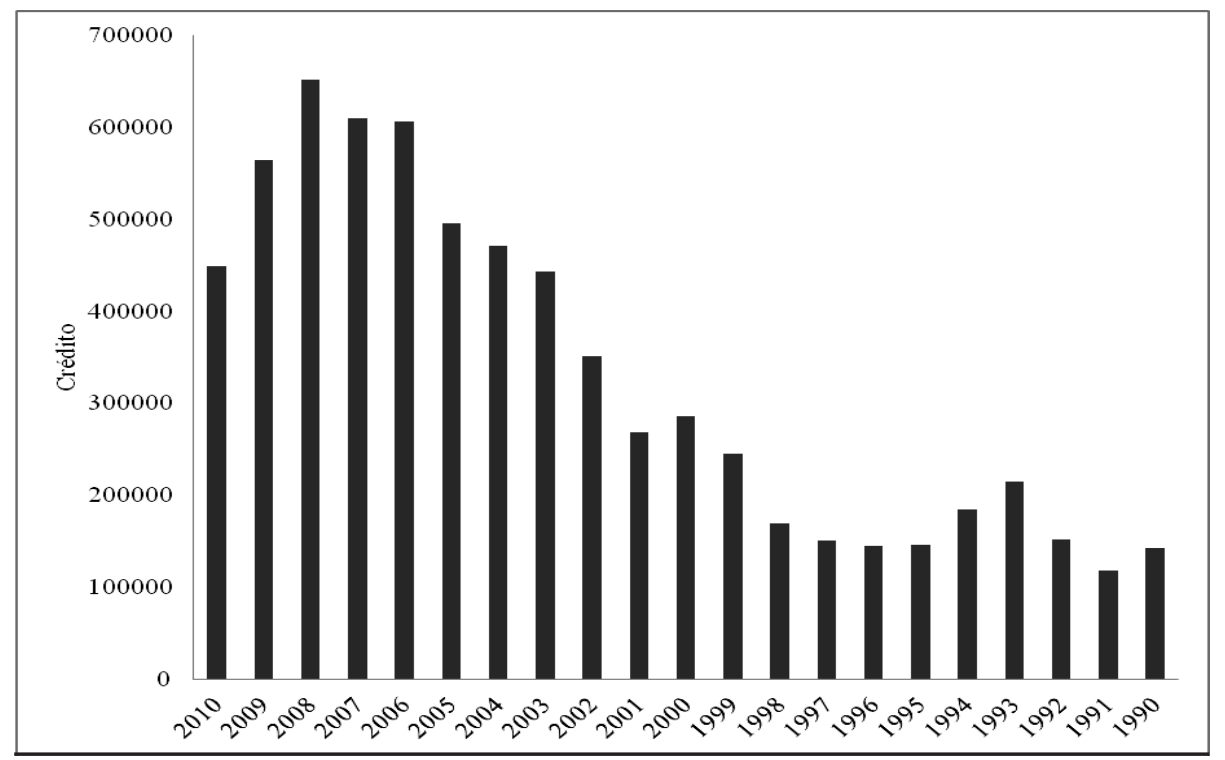

Fuente: Comisión Nacional de Vivienda (2013). 
Aunque existe una variada oferta de a todas las instituciones hipotecarias, el 68 por instituciones hipotecarias (financieras) en ciento de estos créditos fueron otorgados por el México para adquirir una vivienda, la gráfica 3 INFONAVIT, el 11 por ciento por el FOVISSSTE, expone que son el FOVISSSTE e INFONAVIT el 10 por la SHF, el 3 por OREVIS y el resto por quienes concentraron el mayor monto de CONAVI, SHF PROSAVI (Programa Especial de créditos a vivienda nueva. Tal como se explicó antes, la liberalización de los créditos a raíz de la reestructuración de dichos instituciones se manifiesta muy claramente en el territorio mexicano. Aunque son créditos que comprende

Créditos y Subsidios a la Vivienda), SOFOLES, FONHAPO, BANEJÉRCITO, CFE, PEMEX, HABITAT-México y la banca comercial (9 por ciento) (COMISIÓN NACIONAL DE VIVIENDA, 2013).

Gráfica 3 - Crédito para vivienda nueva urbana por institución hipotcaria en México, 19902010

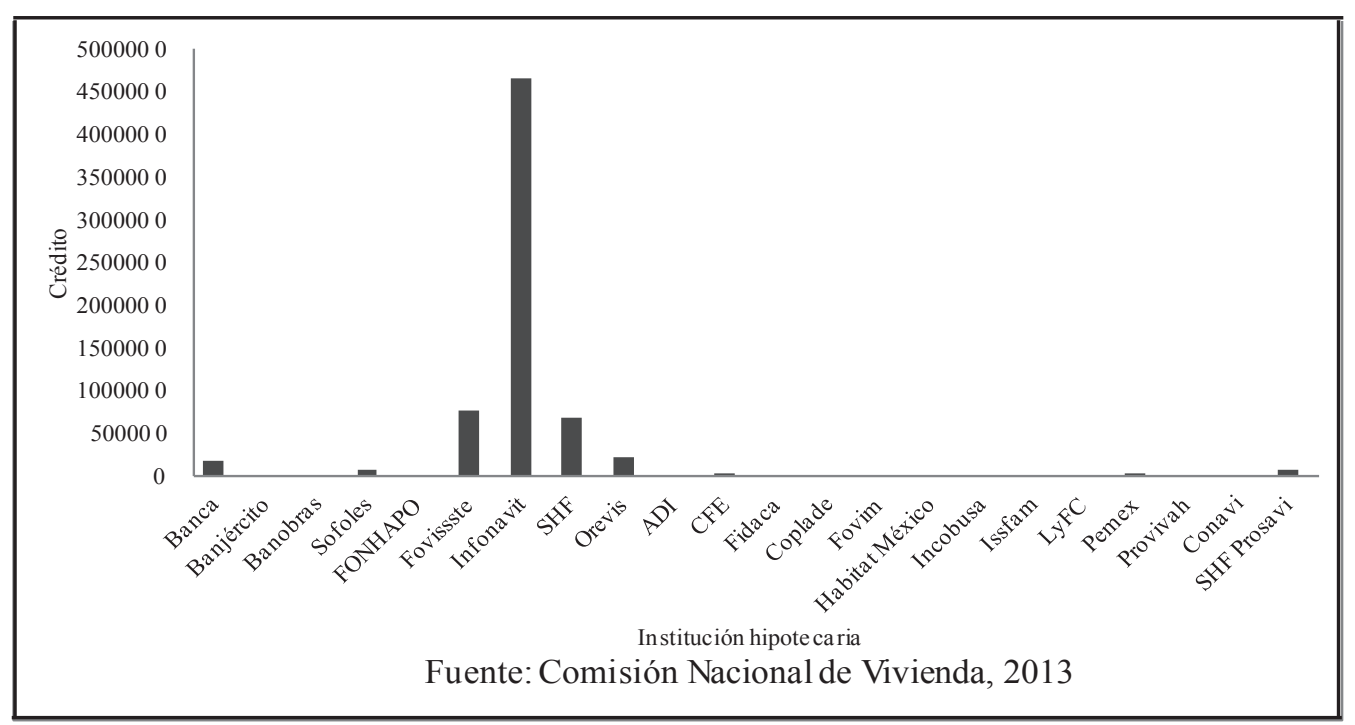

Fuente: Comisión Nacional de Vivienda (2013).

Como FOVISSSTE e INFONAVIT son salarios mínimos mensuales y pertenecer al Instituto instituciones que atienden exclusivamente Mexicano de Seguro Social, IMSS) que pudieran trabajadores del Estado y del sector empresarial respectivamente, queda demostrado que la vivienda nueva fue destinado en su mayoría (79 por ciento) a trabajadores con cierta estabilidad laboral, con ingresos estables (para pertenecer al INFONAVIT por ejemplo, se requiere ingresos mínimos de dos soportar créditos por treinta años y reducciones de su salario por el treinta y cinco por ciento de su percepción salarial mensual. El caso de SHF es similar, requiere de trabajadores con ingresos mayores a tres salarios mínimos y un aval (o trabajo) con cierta estabilidad laboral. 
Gráfica 4 - Créditos Otorgados por Fovisste e Infonavit en México (1990-2010)

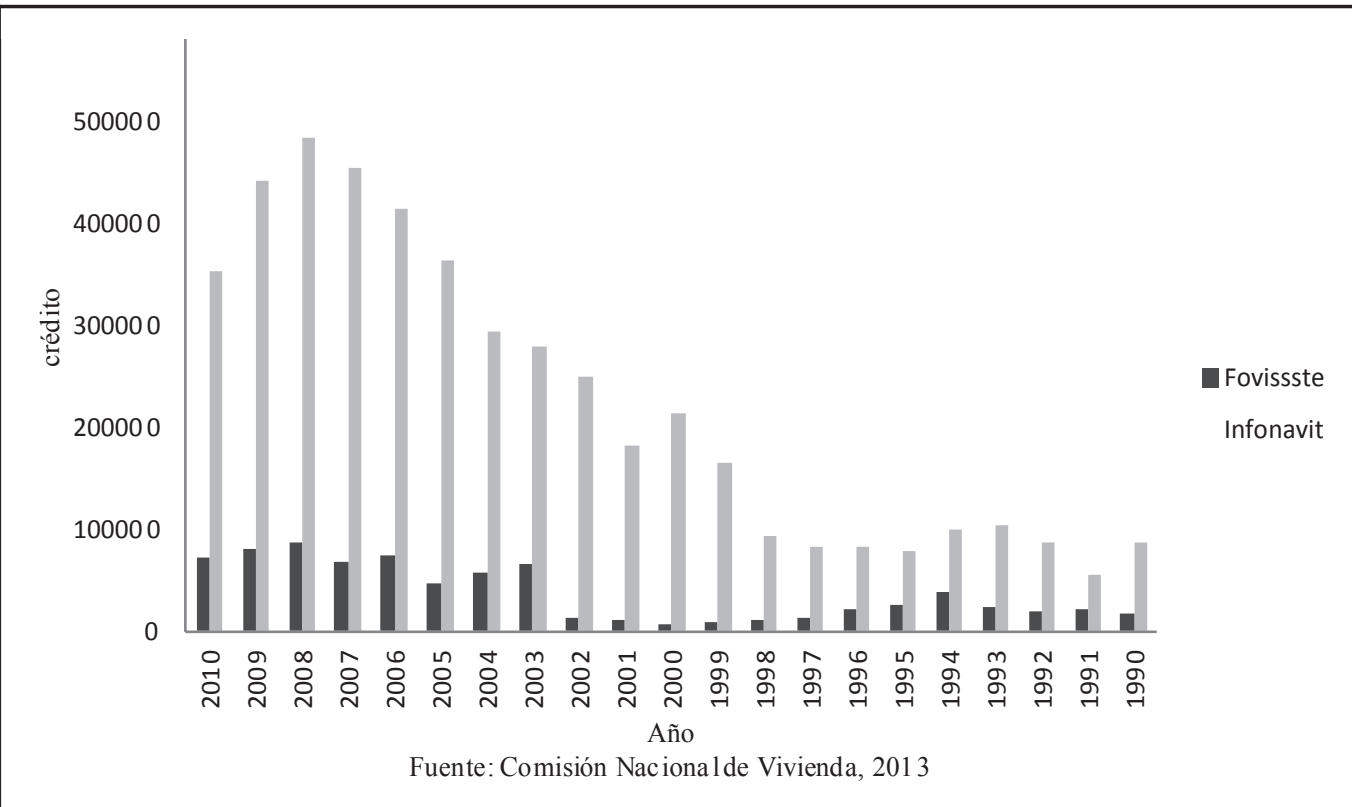

Fuente: Comisión Nacional de Vivienda (2013).

Comportamiento similar tienen los créditos destinados por INFONAVIT y FOVISSSTE en el mismo período en México. Estas instituciones, especialmente la primera, fueron las que determinaron el comportamiento del total de créditos destinados a la vivienda nueva (véase gráfica 4). Adicional a ello, en la primera década del siglo XXI es cuando mayor impulso se da a este tipo de crédito hipotecario: la mayor parte de los créditos en México fueron destinados a personas asalariadas que tienen derecho a un sistema de seguridad social donde una de las principales prestaciones es el derecho a un crédito a la vivienda nueva. Es hasta 2006, cuando se añade la estrategia de otorgar créditos a ampliaciones de vivienda o adquisición de vivienda usada.

México y sus Ciudades. Su Impacto en el Crédito a Vivienda Nueva

México es un país que se considera en transición de ser un país rural a urbano en los últimos cuarenta años. Según los XI, XII y XIII Censos de Población y Vivienda (INSTITUTO NACIONAL DE ESTADÍSTICA Y GEOGRAFÍA, 1992, 2000, 2010), las ciudades mexicanas mayores de cien mil habitantes concentraron el 44 por ciento en 1990, 47 por ciento en 2000 y 48 por ciento en 2010 de la población mexicana, siendo las ciudades de tamaño mediano (de cien mil al millón de habitantes) las que más crecieron, algunas ciudades como Aguascalientes o Cancún tuvieron tasas inusitadas de crecimiento.

Además, son las ciudades mayores a cien mil habitantes quienes concentraron el mayor número de personas económicamente activas (PEA) y ocupadas. En PEA, concentraron el 35 por ciento en 1990, 40 por ciento en 2000 y en 2010,43 por ciento. En población ocupada, las ciudades mexicanas acapararon el 34 por ciento en 1990, 37 en 2000 y 39 por ciento de la población mexicana. Incluso, son las ciudades mayores de cien mil habitantes quienes cuentan con menores porcentajes de personas sin derecho algún servicio social no 
obstante su constante crecimiento (25 por ciento en 2000, 28 en 2005 y 31 en 2010) (INSTITUTO NACIONAL DE ESTADÍSTICA Y GEOGRAFÍA, 2000, 2005, 2010). De eso se deriva que el mayor número de personas ocupadas con derecho a IMSS e ISSSTE (y por consiguiente a derecho a la vivienda a través de INFONAVIT y FOVISSSTE) se concentran en las ciudades mexicanas mayores a cien mil habitantes: en 2000 , el 25 por ciento de la población con derecho a IMSS y 27 por ciento de la población con derecho a ISSSTE; en 2005, similar proporción y en 2010, 34 y 42 por ciento, respectivamente.

Ante esto, se supone que, por lo menos, el setenta por ciento de los créditos destinados a vivienda nueva por el INFONAVIT y FOVISSSTE durante el período analizado, cayeron en las ciudades de análisis. Y esto también puede comprobarse con el destino de la población ocupada y los ingresos percibidos.

De la población ocupada localizada en este tipo de ciudades, en 1990, los servicios acapararon el 29 por ciento, comercio el 12 por ciento, la industria de la transformación un once por ciento, las actividades administrativas públicas (de los tres niveles de gobierno y niveles territoriales) concentran el cinco por ciento, transportes y comunicaciones tres por ciento, industria extractiva uno por ciento y actividades agrícolas otro uno por ciento de la población ocupada. En 2000, la población ocupada cambió muy poco enfocándose principalmente a actividades terciarias, al concentrar el 31 por ciento, diecisiete por ciento dedicado al comercio, industria manufacturera con el doce por ciento y el transporte, comunicaciones, industria extractiva, construcción, electricidad y agua el resto del total. En lo que respecta al año 2010, las actividades de servicios y comercio concentraron el 51 por ciento de la población en estas ciudades, la industria de la transformación el 10 por ciento y el resto fue dividido entre transportes, comunicaciones, industria extractiva, construcción, electricidad y agua (INSTITUTO NACIONAL DE ESTADÍSTICAY GEOGRAFÍA, 1992, 2000, 2010).
En lo referente a ingresos es aún más predominante la concentración en este tipo de ciudades. Durante el período analizado, la proporción de personas ocupadas que reciben más de dos salarios mínimos mejoró levemente (al pasar de 51 por ciento en 1990, 58 por ciento en 2000 a 55 por ciento en 2010) principalmente en el registro del año 2000; no obstante a partir del 2010, el número de personas que recibieron más de cinco salarios mínimo (equivalente a 25 dólares estadounidenses diarios) decayó de 18 por ciento en 2000 al 15 por ciento en 2010 (INSTITUTO NACIONAL DE ESTADÍSTICA Y GEOGRAFÍA, 1992, 2000, 2010). Las políticas de reestructuración productiva ya han dejado su huella al intensificar la desigualdad social mexicana. Aunque todas las ciudades mexicanas sufrieron caídas en el número de personas que reciben más de dos salarios mínimos, algunas lo hicieron menos como Monterrey, Aguascalientes o Zacatecas en contraste de Guadalajara, Ciudad Juárez o Tijuana donde sus caídas fueron las más altas.

No obstante, las proporciones de personas que se encuentran sin empleo también es importante: en 1990, representaba el tres por ciento de la población ocupada, para 2000 era del siete por ciento y en 2010 se incrementó a 9 por ciento. También hubo un aumento en las personas que no recibieron ingreso por concepto de actividades laborales y/o recibieron ingreso menores a dos salarios mínimos. Es decir, las ciudades mexicanas también mostraron indicadores que intensifican una mayor desigualdad social.

Tampoco puede aludirse al bono demográfico y sus tendencias demográficas como justificante para el crecimiento espectacular de la dotación de créditos y viviendas como los supone la Comisión Nacional de Vivienda (2012) y Fundación Centro de Investigación y Documentación de La Casa (2010). Las tasas de crecimiento de la población residente en la ciudades mexicanas en el período analizado no fueron espectaculares (excepto Aguascalientes y Cancún) y no se pronostican que lo sean en los 
próximos años (0.86 en 1990-1995, 0.63 en 19952000 y 0.68 en 2000-2005), cuando su tendencia es al envejecimiento de su población (HAM, 2012).

Salvo los cambios demográficos suscitados por la migración de retorno a causa de la crisis estadounidense iniciada en 2008, las condiciones económicas no son muy prósperas. La economía basada principalmente en la competitividad de exportaciones especializadas (industria maquiladora, automóviles, petróleo y oleaginosas) no son condiciones suficientes para determinar ascendentemente el ritmo de crecimiento de la población.

Pese a los declines sufragados por el proceso de reestructuración productiva que acentúa la flexibilidad y la precarización laboral ya evidentes al final del período en la ciudades mexicanas, el país aún cuenta con un mercado cautivo de personas ocupadas en sectores que durante el período poseyeron derecho al crédito a la vivienda a través del INFONAVIT y FOVISSSTE y con ingresos estables para sustentar créditos hipotecarios hasta de treinta años.

Así, las ciudades mexicanas son las que concentran la mayor cantidad de personas ocupadas económicamente, con los mayores ingresos y con derecho a una vivienda, siendo los principales factores que mueven a la industria inmobiliaria a dedicarse, principalmente al trabajador con derecho a créditos a través de las instituciones especializadas en ello: FOVISSSTE e INFONAVIT.

\section{La Paradoja: Viviendas Deshabitadas}

La mayoría de las ciudades mexicanas (MEJÍA, 1997), tiene un hacinamiento bajo en el número de personas que viven en una vivienda y ha decaído con el paso del tiempo. De 4.95 miembros de un hogar viviendo en una casa en 1990, paso 3.77 en 2010 (INSTITUTO NACIONAL DE ESTADÍSTICA Y GEOGRAFÍA, 1992, 2010). Y la posesión de la propiedad se ha incrementado a pasos agigantados, en 1990, el 59 por ciento de las viviendas ya tenía un propietario; para 2010, se incrementó al 71 por ciento. Por lo menos, y de acuerdo con los censos de población y vivienda del período analizado, existe una proporción extremadamente alta de viviendas particulares en propiedad (o en su caso, que está siendo pagada y que de acuerdo con la percepción del poseedor del crédito, ya es de su propiedad) en las ciudades mexicanas.

Desde esa lógica, las ciudades mexicanas cuentan con indicadores inusuales de propiedad de vivienda y están relacionados al impacto de las políticas de fomento de crédito a la vivienda. En todo caso, esto significa que las ciudades mayores de cien mil habitantes están muy cerca de cumplir sus metas de vivienda propia y nueva para la mayor parte de la población ante el bajo nivel de hacinamiento y alta proporción de propiedad de la vivienda. $\mathrm{O}$ en su defecto, existen residentes que tienen varias viviendas.

La gráfica 4 expone el creciente volumen de viviendas construidas en México y en las ciudades analizadas durante el período y la proporción de viviendas particulares deshabitadas. Para 1990 equivalía tanto para México como para las ciudades al 9 por ciento del total de viviendas, para 2000 se incrementó a 13 y para el 2010 fue del 21 por ciento. 
Gráfica 5 - Viviendas totales, habitadas y deshabitadas en ciudades mayores a 100 mil habitantes y México, 1990-2010

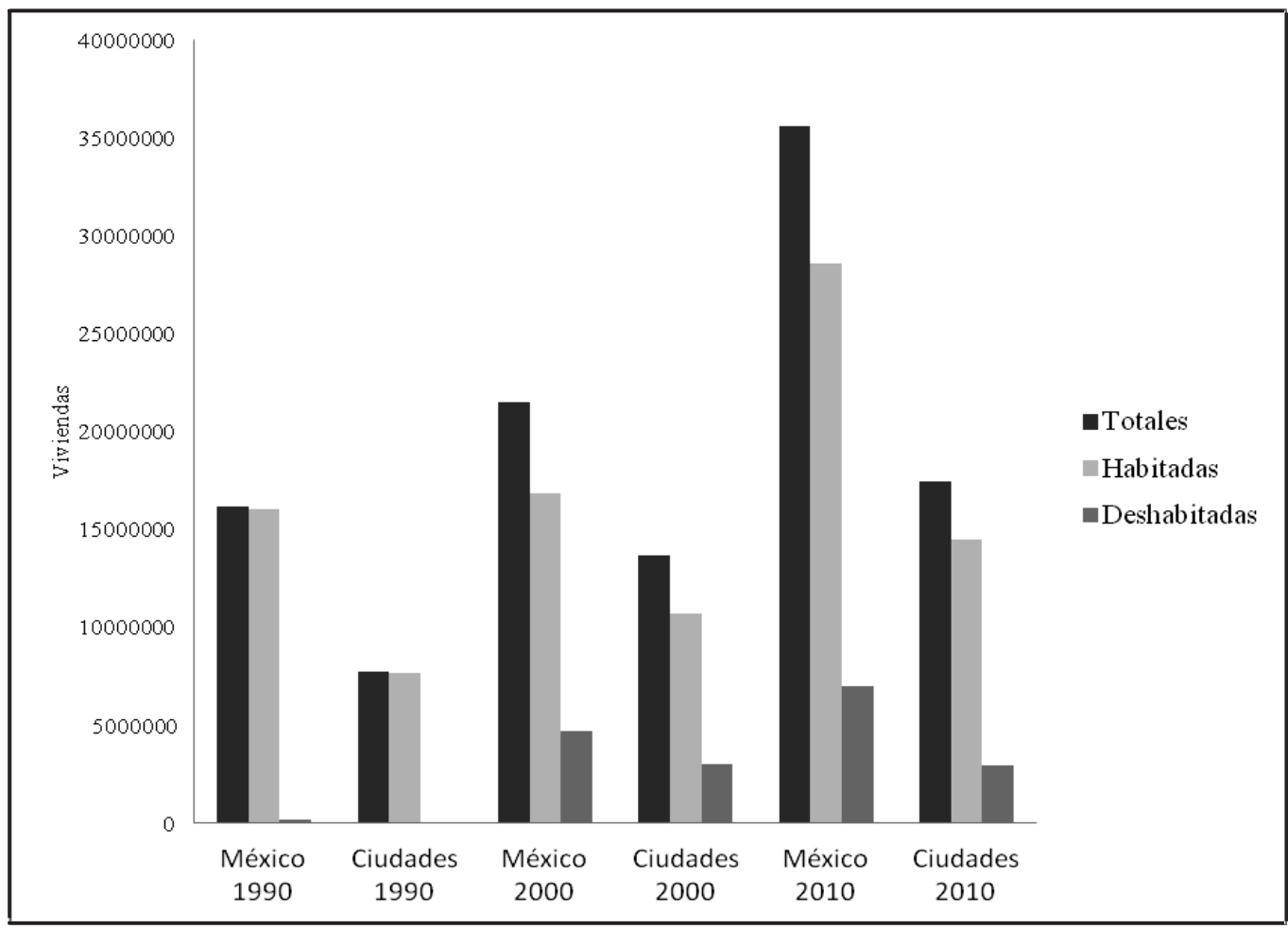

Fuente: Instituto Nacional de Estadística, Geografía e Informática (1992, 2000, 2010).

De acuerdo con el trabajo de campo realizado en algunos fraccionamientos donde se han aplicado los créditos, las viviendas deshabitadas responden a varios factores: lejanía respecto a sus centros de trabajos, actividades sociales, económicas, políticas y sobretodo familiares en otras zonas de la ciudad; mala calidad de la vivienda y el medio circundante considerado inseguro; provisión deficiente de servicios públicos (agua, energía eléctrica, alumbrado, transporte, equipamiento escolar $\mathrm{o}$ comercial), emigración a otras ciudades en busca de oportunidades laborales, insolvencia para pagar el crédito de la vivienda ya sea por pérdida de trabajo o aumento del costo, y, en especial, la no necesidad de la vivienda.

En la mayoría de los casos revisados, se obtuvo la vivienda para "aprovechar el crédito", para "tener una casa para rentarla", para "tenerla por sí se llegara a necesitar", para "posteriormente venderla". A causa de que la mayor parte de los beneficiarios de esas viviendas son personas que cuentan con ingresos mayores a dos salarios mínimos, muchos de ellos ya cuentan con otra propiedad obtenida bajo otros medios. La mayor parte de la vivienda deshabitada otorgada por el INFONAVIT o FOVISSSTE no es necesaria o no es de primordial necesidad poseerla o utilizarla por el propietario.

Según la gráfica 2, la liberalización del crédito fue más evidente desde el año dos mil, pero su punto álgido fue 2008. La plenitud de las viviendas deshabitadas se dio en 2010. Los datos para México en el año 2010 publicados por el Instituto Nacional de Estadística y Geografía (INEGI) son evidencia: 4'997,806 viviendas están deshabitadas y 2'012,350 se usan temporalmente. Desde el año dos mil, éste dato se incrementó en 4850 por ciento. En lo referente a las ciudades mayores a cien mil habitantes, el fenómeno es similar: 2'211,962 
viviendas deshabitadas y 737,320 de uso temporal en 2010, que equivale un incremento del 99 por ciento respecto al año dos mil (INSTITUTO NACIONAL DE ESTADÍSTICA Y GEOGRAFÍA, 2000, 2010). Fenómeno que aún resulta sorprendente para las instituciones hipotecarias (GARCÍA, 2012; LÓPEZ 2012; MANILLA 2013; RÍOS, 2013; SORPRENDE..., 2011; TORRES, 2013; VILCHES, 2013).

Para sustentar la afirmación que se ha desarrollado, se relacionó a través del Coeficiente de Correlación de Pearson a las viviendas deshabitadas con las personas que recibieron ingresos por motivos laborales entre dos y cinco salarios mínimos y personas que recibieron más de cinco salarios mínimos por motivos laborales en las ciudades mexicanas mayores de cien mil habitantes para el año 2010 (INSTITUTO NACIONAL DE ESTADÍSTICA Y GEOGRAFÍA, 2010)². Los resultados indican que existe correlación de 0.29 entre la vivienda deshabitada y población ocupada que recibe entre dos y cinco salarios mínimos a un nivel de significancia de 0.000; mientras que la correlación entre la población ocupada que recibe ingresos mayores a cinco salarios mínimos y la vivienda deshabitada es de 0.262 a similar nivel de significancia.

Ante esos resultados, la vivienda deshabitada estuvo asociada a la población ocupada que recibe ingresos mayores a dos salarios mínimos en las ciudades mexicanas mayores a cien mil habitantes para el año 2010. Concretamente, influyó más la población ocupada que recibe entre dos y cinco salarios mínimos, esto se debe a que en el año 2010, el cuarenta y nueve por ciento de la población ocupada en las ciudades mexicanas se encontró en esa categoría.
Finalmente, para conocer la magnitud de la determinación, se aplicó la técnica de regresión no lineal (a través del método de curva de estimación) donde arrojó el siguiente modelo:

vivsola $=51.8+0.229 \log Y_{25 s m}+0.198 \log Y_{m 5 s m}+e$

Sustento que indica que fueron los residentes de las ciudades mayores a cien mil habitantes con ingresos mayores a dos salarios mínimos quienes pudieron fomentar la abundancia de viviendas deshabitadas a través de su facilidad en obtener créditos hipotecarios. Concretamente, aquellos con ingresos entre dos y cinco salarios mínimos causaron mayor determinación.

Las ciudades mexicanas mayores a cien mil habitantes (la mayoría son capitales de estados) que administran recursos federales, estatales y municipales, concentra un importante conglomerado de empleados burocráticos y empleados privados que, bajo la ley de trabajo constantemente reformulada, aún presenta ciertas prestaciones sociales como la del derecho a la vivienda. Los pobladores de este tipo de ciudades poseyeron libertad y mayor disposición de utilizar un crédito a la vivienda como derecho laboral, situación que no comparten ciudades menores a cien mil habitantes y zonas rurales debido a su orientación económica (economía campesina de subsistencia, ganadería, minería, comercio al por menor) y su pobre capacidad receptora de ingresos.

No obstante, de acuerdo con la Comisión Nacional de Vivienda (2012), las ciudades mayores a cien mil habitantes demandaron viviendas nuevas por 519,063 en 2006; 523,058 en 2007; 526,113 en 2008; 526,564 en 2009 y 526,399 en 2010. Una demanda que por mucho ha sido superada con 607,172 créditos otorgados en 2006; 610,100 en 2007; 652,659 en 2008; 564,295 en 2009 y

\footnotetext{
${ }^{2}$ A través del cuestionario base se obtuvo información sobre la población ocupada que recibe ingresos por haber laborado en 2010. Estos datos fueron, estandarizados y calculados para las ciudades que no disponían de datos bajo la tasa de crecimiento geométrico (INSTITUTO NACIONAL DE ESTADÍSTICA Y GEOGRAFÍA, 1997).
} 
448,956 en 2010 (COMISIÓN NACIONAL DE VIVIENDA, 2013).

Aunque la demanda sigue siendo calculada bajo el esquema del derecho a la vivienda, el destino de los créditos tiene objetivos distintos: rentabilidad, estabilidad y seguridad que proporciona el derechohabiente localizado principalmente en las ciudades mayores a cien mil habitantes. La demanda de vivienda seguirá su curso; muy distinto al de la construcción y financiamiento de la vivienda.

Los demandantes de vivienda digna, los pobladores con ingresos precarios, seguirán solicitando programas de fomento a la vivienda acorde a sus posibilidades (el FONHAPO apenas cubrió el 0.019 por ciento de los créditos otorgados de 1990 a 2010 en el país). Mientras, las instituciones privadas y públicas hipotecarias difundirán sus desarrollos habitacionales y sus políticas de financiamiento sobre los pobladores que no las demandan pero las pueden adquirir.

\section{Conclusiones}

El exceso de viviendas no es precisamente por un mal cálculo en proyecciones de financiamiento a viviendas, en realidad se trata de inversiones de capital excedente que busca rentabilizarse. El exceso de casas nuevas deshabitadas corresponde a la liberalización del crédito desde el cambio de dirección en la política de vivienda donde ahora, a través de la Sociedad Hipotecaria Federal (SHF), los derechohabientes pueden acceder a una vivienda de acuerdo a un crédito estipulado a las normas laborales, mientras que anteriormente el INFONAVIT y el FOVISSSTE proveían la vivienda en físico.

La política de fomento a la vivienda no corresponde al derecho a la vivienda, sino a la política de fomento al capital inmobiliario, que busca, a través de la gestión y regularización del Estado, rentabilizar en el mercado del suelo bajo la tutela de la vivienda. Y esto no es nuevo, ya Engels
(1873) recalcaba que la buena voluntad de los capitalistas industriales de proveerles una vivienda cercana a los trabajadores no era por ser personajes de alta moral, sino porque era un negocio muy rentable.

Por tanto, el derecho a la vivienda es un problema político más que un valor universal de bienestar. Se trata de la disputa por la apropiación de beneficios de un derecho establecido por la democracia liberal. Proveer a los trabajadores con cierta seguridad laboral una vivienda, sin considerar si le es necesaria o útil, responde a la necesidad de rentabilizar capitales que buscan donde reproducirse.

Aunque no existe aún evidencia de una crisis inmobiliaria, el exceso de viviendas en la mayoría de las ciudades mexicanas ha causado estragos. Al apego de los datos, el punto de quiebre fue el 2008, con un consecuente caída en la dotación de créditos. Símbolo de una posible saturación del mercado.

Aunque no es el objetivo del presente analizar las consecuencias del excedente de viviendas, es necesario por lo menos enunciar: el desperdicio de recursos de todo tipo (ambiental, económico, material), la expansión de la ciudad sin regulación, control ni planeación, algo poco probable en una sociedad capitalista, la generación de fenómenos que aluden a la criminalidad, violencia y abuso (robos, focos de posibles creación de bandas o pandillas), focos de infección, y otros referidos al impacto de la formación de la fuerza de trabajo: la incapacidad de pago de la vivienda a causa del incremento del costo hipotecario, por un lado y la pérdida de trabajo, por el otro. Fenómenos que tendrá que resolver la institución estatal y la sociedad bajo la socialización de costos, mientras los beneficios son privatizados por el capital inmobiliario, como lógica de la dinámica capitalista actual. 


\section{Referencias}

COMISIÓNNACIONALDEVIVIENDA-CONAVI.

Cierres definitivos de vivienda 1973-2011. 2013.

Disponible en: <http://www.canadevivallemexico. com/documentos/Instituciones_Financieras/Conavi/ cierres_definitivos_en_vivienda/001.pdf $>$. Acceso en: 16 ene. 2013.

- Necesidades de vivienda 2006-2012.

Disponible en: <http://www.conavi.gob.mx/ documentos/politica/Necesidades_2006_2012.pdf $>$. Acceso en: 16 ene. 2013.

DUCCI, M. Chile: el lado obscuro de una política de vivienda exitosa. Eure, Santiago de Chile, v. 23, n. 69, p. 99-115, jul. 1997.

ENGELS, F. Contribución al problema de la vivienda. In: MARX, K.; ENGELS, F. Obras escogidas. Moscovo: Progresso Lisboa, 1873. t. 2. p. 314-396.

ETCHEGARAY, A. Vivienda, democracia y equidad. In: ETCHEGARAY, A. et al. Las reformas sociales en acción: vivienda. Santiago de Chile: CEPAL, 1997. p. 9-16. (Serie Políticas Sociales n. 20).

FUNDACIÓN CENTRO DE INVESTIGACIÓN Y DOCUMENTACIÓN DE LA CASA. Estado actual de la vivienda en México. Ciudad del Mexico, 2010.

GARCÍA, B. Vivienda social en México (19401999). Cuadernos de Vivienda y Urbanismo, Bogotá, v. 3, n. 5, p. 34-49, 2010.

GARCÍA, S. Problema por viviendas solas. Tribuna de San Luis, Río Colorado, 7 abr. 2012.

GONZÁLES, G. El crédito hipotecario y el acceso a la vivienda para los hogares de menores ingresos en América Latina. Santiago de Chile: CEPAL, 2002. (Serie Financiamiento del Desarrollo, n. 122).

HAM, R. Diagnóstico socio-demográfico del envejecimiento en México. In: CONSEJO NACIONAL DE POBLACIÓN. La situación demográfica de México 2011. Cuidad del Mexico: Consejo Nacional de Población, 2012. p. 141-155.
INSTITUTO NACIONAL DE ESTADÍSTICA Y GEOGRAFÍA. XI Censo general de población y vivienda 1990: tabulados básicos por localidad. Aguascalientes, 1992.

- Manual de medidas sociodemográficas.

Aguascalientes, 1997.

- XII Censo general de población y vivienda 2000: tabulados básicos por localidad. Aguascalientes, 2000.

. II Conteo de población y vivienda 2005: tabulados básicos por localidad. Aguascalientes, 2005.

- XIII Censo general de población y vivienda 2010: tabulados básicos por localidad. Aguascalientes, 2010.

LÓPEZ, N. Detectan 3 mil casas solas. Noroeste, Culiacán, 10 sept. 2012. Sección local.

MANILLA, E. Crece el número de viviendas solas. El Mañana, Ciudad Victoria, 16 Ene. 2013. Sección local.

MEJÍA, J. La política de vivienda en México. In: ETCHEGARAY, A. et al. Las reformas sociales en acción: vivienda. Santiago de Chile: CEPAL, 1997. p. 29-34. (Serie Políticas Sociales, n. 20).

MEXICO. Presidencia de la República. Plan nacional de desarrollo 2007-2012. Ciudad del Mexico: Gobierno de los Estados Unidos Mexicanos, 2007.

O'SULLIVAN, A. Urban economics. 3. ed. Boston: Irvin/McGraw Hills, 1996.

RÍOS, P. M. Hay casi 5 millones de viviendas abandonadas en todo el país. La Jornada, Ciudad del Mexico, 9 abr. 2013. Sección Sociedad y Justicia.

RODRÍGUEZ, A.; SUGRANYES, A. El problema de vivienda de los 'con techo'. Eure, Santiago de Chile, v. 30, n. 91, p. 53-65, Dic. 2004.

- Vivienda privada de la ciudad. Revista de Ingeniería, Bogotá, n. 35, p. 100-107, jul./dic. 2011.

SÁNCHEZ, J. La vivienda "social" en México: pasado, presente y futuro. Ciudad del Mexico: JSa, 2012. 
SORPRENDE a sector cifra de viviendas solas. Milenio, Ciudad del Mexico, 14 mar. 2011. Sección Estados.

TORRES, R.; EIBENSCHUTZ, R. Dimensión e impactos macro y microeconómicos de la producción social de vivienda en México. Ciudad del Mexico: CONACYT, 2005.

TORRES, Y. Deshabitadas, 14\% de las viviendas en México. El Economista, Ciudad del Mexico, 30 abr. 2013.

VILCHES, D. Plantean otorgar viviendas deshabitadas a policías. Milenio, Ciudad del Mexico, 30 abr. 2013. Sección Estados. 